\title{
The Role of Striatum in Initiation and Execution of Learned Action Sequences in Rats
}

\author{
Kathleen R. Bailey and Robert G. Mair \\ Department of Psychology, University of New Hampshire, Durham, New Hampshire 03824
}

To understand the role of striatum in motor sequence learning, we trained rats to perform a series of tasks measuring speed and accuracy of responding to luminance cues presented as discriminative stimuli for single nose pokes or for sequences of nose pokes in a serial reaction time task. Habit (stimulus-response) learning was measured by comparing performances when stimuli were repeated (predictable) with when they were selected randomly (unpredictable). Sequences had defined start and end points and were limited to five nose pokes to minimize chunking. When sequences were repeated, response time (RT) increased for nose pokes initiating the sequence and decreased for nose pokes completing it. These effects developed incrementally across sessions, consistent with the time course of habit learning. Medial $(\mathrm{mCPu})$, lateral, and complete $(\mathrm{CPu})$ caudate-putamen lesions affected speed and accuracy of single nose poke responses, confirming the role of these areas in guiding responses with external sensory stimuli. None of these lesions affected the short-term increase in accuracy observed when single nose poke responses were repeated. Both $\mathrm{mCPu}$ and $\mathrm{CPu}$ lesions increased RTs for initiating sequential responses, effects that were exacerbated across sessions in which specific sequences were repeated. None of the lesions affected the gradual decrease in RT for nose pokes completing repeated sequences. Correlational analyses confirmed the relationship between the extent of dorsal striatal damage and the ability to respond to brief luminance cues and to initiate learned sequences. These results provide evidence implicating dorsal striatum in higher-level organizational aspects of learning reflected in planning that precedes the execution of learned action sequences.

Key words: caudate-putamen; ventral striatum; serial reaction time; motor programming; habit learning; motor control

\section{Introduction}

Many routine behaviors, such as typing familiar words or shifting gears in a car, consist of sequences of discrete actions performed seamlessly as an organized response. Organisms perfect action sequences gradually with practice through an implicit learning process. Much of what is known about how this happens has come from serial reaction time tasks in which subjects respond as quickly as possible to a series of stimuli, with each response activating the next stimulus in the sequence. Implicit learning is measured by decreases in response time (RT) to complete a specific sequence when it is presented repeatedly unbeknownst to the subject.

Convergent evidence suggests that the basal ganglia play an important role in this type of learning. Clinical studies have shown serial reaction time learning deficits in both Parkinson's (Jackson et al., 1995; Dominey et al., 1997; Smith and McDowall, 2004) and Huntington's (Knopman and Nissen, 1991; Willingham and Koroshetz, 1993; Brown et al., 2001) diseases. Func-

\footnotetext{
Received Sept. 13, 2005; revised Dec. 5, 2005; accepted Dec. 6, 2005.

This work was supported by National Institute of Neurological Disorders and Stroke Grant NS26855. It constituted partial fulfillment of the degree requirements for a PhD at the University of New Hampshire for K.R.B. We thank Rob Cioffi for writing computer programs for serial reaction time training and data analysis; Meg Toupin for histological processing and laboratory supervision; and Andria Dobberstein, Zita Torok, Rob Cioffi, Rob Mair, Meg Enos, Lauren Crouse, Shana Driscoll, Ashley Ward, Gerald Moothart, Tyler Langenderfer, Ben Kushner, and Jason Martin for assistance with training animals.

Correspondence should be addressed to Robert G. Mair at the above address. E-mail: rgm@unh.edu.

DOI:10.1523/JNEUROSCI.3883-05.2006

Copyright $\odot 2006$ Society for Neuroscience $\quad$ 0270-6474/06/261016-10\$15.00/0
}

tional imaging studies have confirmed the involvement of the basal ganglia in implicit serial reaction time learning in diverse populations of human subjects (Rauch et al., 1997; Peigneux et al., 2000; Daselaar et al., 2003; Kim et al., 2004). Recording studies in nonhuman primates have shown changes in neural activity in striatum that correspond to visuomotor sequence learning, an involvement confirmed by behavioral impairments observed when striatum is reversibly inactivated (Miyachi et al., 1997, 2002). Caudate-putamen lesions in rats have been found to disrupt serial reaction time learning measured by interference effects, increases in RT observed when subjects trained with a repeating sequence are switched to random sequences (Christie and Dalrymple-Alford, 2004).

Reaction time analyses suggest two distinct effects of performing a fixed series of actions repeatedly. First, learning to perform a series of independent actions as a coherent sequence (or chunk) requires higher-order organizational processes to program the response before its execution and thus should increase RT for the first elements of a practiced sequence (or chunk of a longer sequence) (Sternberg et al., 1978; Inhoff et al., 1989; Kennerley et al., 2004). Second, habit learning should gradually benefit the execution of repeated actions, reducing overall RT as sequences are practiced (Nissen and Bullemer, 1987; Nissen et al., 1989; Christie and Dalrymple-Alford, 2004). We hypothesize that motor sequences create cascades of stimulus-response (S-R) links, with each action influencing all subsequent responses and thus augmenting the effects of S-R habit learning for later elements in a well practiced sequence. 
Table 1. Sites of injections ( $0.1 \mu \mathrm{l}$ of $100 \mathrm{~mm}$ NMDA)

\begin{tabular}{llll}
\hline Lesion & Anteroposterior & Mediolateral & Dorsoventral \\
\hline ICPu, Cpu & +1.7 & \pm 3.0 & $4.0,4.8,5.6$ \\
& +1.0 & \pm 3.4 & $4.0,4.8,5.6$ \\
& +0.3 & \pm 3.8 & $3.4,4.5,5.6$ \\
& -0.4 & \pm 4.2 & $3.4,4.2 .5 .2$ \\
$\mathrm{mCPu}, \mathrm{CPu}$ & +1.7 & \pm 2.0 & $4.0,5.0,6.0$ \\
& +1.0 & \pm 2.2 & $4.0,5.0,6.0$ \\
& +0.3 & \pm 2.4 & $3.0,4.5,6.0$ \\
& -0.4 & \pm 2.6 & $4.0,5.0,6.0$ \\
VSt & +2.7 & $\pm 1.0,2.0$ & 3.0 \\
& +1.7 & $\pm 1.0,2.0$ & $2.0,3.0$ \\
& +0.7 & $\pm 1.0,2.0$ & $1.8,2.8$ \\
\hline
\end{tabular}

Coordinates were measured in millimeters from bregma for anteroposterior, on each side of midline for mediolateral, and above the interaural line for dorsoventral. The CPu lesion combined the sites used for the ICPu and mCPu lesions.

To study sequence learning, we developed a serial reaction time task in which rats received water reinforcement after making a series of nose pokes in ports indicated by luminance cues. To determine the role of the basal ganglia in this task, we compared the effects of lesions in functionally distinct parts of striatum. To distinguish between the effects of lesions on response initiation and execution, we analyzed RTs for individual nose pokes in series of repeating or random sequences.

\section{Materials and Methods \\ Animals}

Subjects were 43 male Long-Evans rats that were 7 weeks of age at the onset of behavioral training and 43 weeks of age after completion of postsurgical training. Rats were housed individually in a temperatureand humidity-controlled vivarium on a $12 \mathrm{~h}$ light/dark cycle with all behavioral training occurring during the light phase. Access to water was restricted so that it could be used to reinforce responding. Rats had access to water during behavioral training and for $30 \mathrm{~min}$ at the end of the light cycle each day. Water access was increased to $60 \mathrm{~min}$ on nontraining days. Rats were trained to perform the basic RT task to criteria and then assigned randomly to one of five surgical treatments: complete caudateputamen lesion $(\mathrm{CPu})$, medial caudate-putamen lesion $(\mathrm{mCPu})$, lateral caudate-putamen lesion ( $1 \mathrm{CPu}$ ), ventral striatal lesion (VSt), and shamoperated control. Initially, eight rats were assigned per group; however, three additional rats were assigned to the $\mathrm{CPu}$ group after one died during early postsurgical recovery. Thus, after recovery from surgery, there were 10 rats in the $\mathrm{CPu}$ group and eight in each of the others. After surgery, rats were tested for basic RT performance, and then the effects of stimulus repetition were studied for single nose pokes and then sequences of nose pokes in a serial reaction time task.

\section{Surgery}

Rats were anesthetized with intramuscular injections of ketamine (85 $\mathrm{mg} / \mathrm{kg})$ and xylazine $(8.5 \mathrm{mg} / \mathrm{kg})$ and positioned in a stereotaxic instrument (David Kopf Instruments, Tujunga, CA) with the incisor bar set 3.3 $\mathrm{mm}$ below the interaural line. Using aseptic procedures, skulls were opened and lesions produced by injecting $0.1 \mu \mathrm{l}$ of NMDA (100 mM in phosphate buffer, $\mathrm{pH}=7.4)$ at the desired locations with a 26-gauge cannula $(0.2 \mu \mathrm{l} / \mathrm{min})$ using a Kopf 5000 microinjection unit. The cannula was left at each site for $1 \mathrm{~min}$ after the injection. The incision was sutured shut after the last NMDA injection. The stereotaxic coordinates of injection sites for the lesions are listed in Table 1. Sham surgery on controls consisted of the same preliminary surgical procedures without opening the skull. The VSt group effectively served as surgical controls. Previous results in our laboratory showed that VSt lesions spare the present RT task while producing substantial deficits for measures of prefrontaldependent spatial memory (Burk and Mair, 2001; Mair et al., 2002). We did not expect VSt lesions to affect any of the present RT tasks. Animals were monitored during 2 weeks of postsurgical recovery before water restriction and behavioral training resumed.

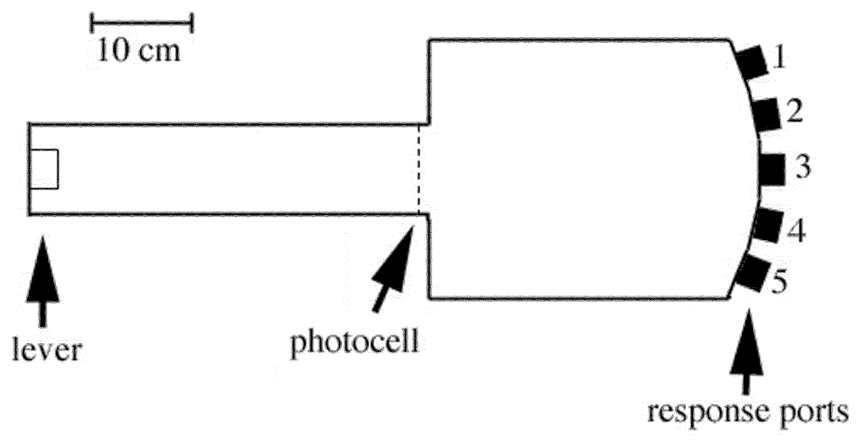

Figure 1. Scaled drawing of the apparatus used for behavioral training. For all tasks, trials began with a press of the retractable lever. Luminance cues (from lights centered at the back of each port) were then triggered when rats next crossed the photocell before entering the main chamber. Water was delivered in wells in the floors of response ports to reinforce correct responding.

\section{Apparatus}

We trained rats in apparatus (Fig. 1) consisting of a rectangular test chamber (Env 008) with five response ports spaced evenly across a panel (Env 115A) on one side and a runway alley (Env 542) centered on the opposite side (all purchased from Med Associates, Georgia, VT). Each response port was equipped with a stimulus light, a photo beam positioned to detect nose pokes, and a stainless-steel receptacle in which tap water was delivered as a reinforcement by activation of a miniature solenoid valve (LFAA1201518H; The Lee Co., Essex, CT). There was a photo beam positioned across the alley adjacent to where it joined the test chamber and a retractable lever (Env 215A) at the far end of the alley. These apparatus were housed in plywood sound-insulating boxes and were controlled remotely by a computer located in another room.

\section{Procedure}

Presurgical training. Rats were trained to perform the single nose poke RT task as described previously (Bailey and Mair, 2004). Trials began with the lever extending at the far end of the alley. This was retracted when pressed, causing lights to turn on in all five response ports. When rats then crossed the runway photo beam (just before re-entering the test chamber from the alley), lights turned off immediately in four $(\mathrm{S}-$ ) ports and after a variable delay $(0.05,0.11,0.26,0.58,1.33,3.0 \mathrm{~s})$ in the fifth $(\mathrm{S}+)$ port. The location of the $\mathrm{S}+$ port and the length of the delay were selected randomly for each trial. Reinforcement (two $0.1 \mathrm{ml}$ pulses of tap water) was delivered when rats responded to the $S+$ port within $3.0 \mathrm{~s}$ of crossing the runway photo beam (the limited hold) without previously responding to an $\mathrm{S}-$ port. Responses were recorded as correct when reinforcement was delivered, errors of omission when no response was made within the $3.0 \mathrm{~s}$ limited hold, or errors of commission when an incorrect response was made within the limited hold. Presurgical training continued until rats completed 96 trials with $70 \%$ correct (averaged across stimulus durations) during each of three consecutive $60 \mathrm{~min}$ training sessions.

Postsurgical training: single nose poke responding. After 2 weeks of recovery from surgery, single responding was re-established for five sessions with the stimulus light remaining on for the duration of the $3.0 \mathrm{~s}$ limited hold on all trials. After this, responding was tested with variable stimulus durations for 10 sessions using the same procedures as immediately before surgery.

Postsurgical training: short-term effects of repeating single nose poke responses. Short-term learning was then tested by holding the location of the $S+$ port constant for seven consecutive trials. Trials were again initiated by a lever press at the end of the alley and reinforcement given for a nose poke in the port indicated by a stimulus light within a $3.0 \mathrm{~s} \mathrm{limited}$ hold. In this task, however, the S+ light was turned on when the alley photo beam was crossed and the lights in the $S$ - ports were never turned on. The location of the $S+$ port was held constant during each block of seven trials and then was shifted randomly to one of the four other ports for the next block. The length of the $\mathrm{S}+$ stimulus alternated between brief ( $0.05 \mathrm{~s}$; trials $1,3,5$, and 7 of each block) and long ( $3.0 \mathrm{~s}$; trials 2, 4, and 6$)$ 
durations. The long duration trials were intended to guarantee that rats made consistent correct responses on trials 2, 4, and 6 from which they could benefit on trials 3,5 , and 7 . Habit learning was measured by the response accuracy and RT responding the $0.05 \mathrm{~s}$ stimuli and RT for $3.0 \mathrm{~s}$ stimuli.

Postsurgical training: long-term effects of repeating single nose poke responses. Long-term learning was next measured for single nose poke responses by comparing RT to respond during sessions in which the location of the $\mathrm{S}+$ port remained the same for all trials to sessions in which the location of the $S+$ port changed randomly on each trial. Each of these sessions consisted of 50 trials with a stimulus duration of $3.0 \mathrm{~s}$ on each trial. Rats were trained for one session with randomly changing $\mathrm{S}+$ locations, five sessions in which $\mathrm{S}+$ was kept in a single fixed location, and then one session with randomly changing $\mathrm{S}+$ locations. There was no limited hold.

Postsurgical training: effects of repetition on serial reaction time nose poke sequences. Serial reaction time was next tested by requiring rats to respond to a series of five ports before receiving reinforcement. Trials began with a lever press. The first $S+$ stimulus turned on when the arm photocell was crossed and remained on until a nose poke occurred in the $S+$ port. This caused the light in that port to turn off and the light in the next $\mathrm{S}+$ port to turn on. This process continued for a total of five $\mathrm{S}+$ stimuli. Reinforcement (two $0.1 \mathrm{ml}$ pulses of tap water) was delivered (and the trial ended) after a nose poke into the fifth $S+$ port of the sequence. Serial reaction time was trained for 60 trials per session.

Rats were first trained with different (randomly selected without replacement) sequences on every trial until performances stabilized (five sessions). They were then tested for one session with random sequences (session R1), five sessions in which the same sequence (sequence A) was repeated on every trial (sessions A1 to A5), a second session with new randomly selected sequences on each trial (session R2), five more sessions with sequence A on every trial (sessions A6 to A10), a third session with new randomly selected sequences (session R3), five sessions with a different repeating sequence (sequence B) on every trial (sessions B1 to $\mathrm{B} 5$ ), and then a fourth session with new randomly selected sequences on every trial (session R4). Selecting a series of five ports randomly without replacement from the five possibilities will result in 120 possible orders with an average travel distance of two ports for each response after the initial S + . To ensure travel distances comparable with this average, repeated sequences were constructed so that each $S+$ was two ports from the previous $\mathrm{S}+$. This also equalized travel distances for each step in repeated sequences. With the numbering of ports in Figure 1, repeated sequence A consisted of 3-1-3-5-3 (left 2, right 2, right 2, then left 2 ports from the initial response to port 3 ) and sequence B of 2-4-2-4-2 (right 2, left 2 , right 2 , then left 2 ports from the initial response to port 2 ). Serial reaction time performance was assessed by measuring the RT for each of the five responses in a trial. Sequence-specific learning was assessed by comparing performances for repeating sequences within and between sessions and by measuring interference effects when training switched from repeating to random sequences.

Statistical analysis. Dependent variables included percentage correct and RT, measured as median RT for individual animals in a session or in a block of trials within a session (for analyses of within-session performance). Behavioral performance was analyzed using mixed-model ANOVAs with treatment group as a between-subjects factor and taskrelated variables as within-subject factors. For significant test results involving within-subject factors in which the sphericity assumption was violated, the conservative Greenhouse-Geisser adjusted probability was reported. When the between-subjects variable proved significant, group means were examined using the Tukey-Kramer post hoc test $(\alpha=0.05)$.
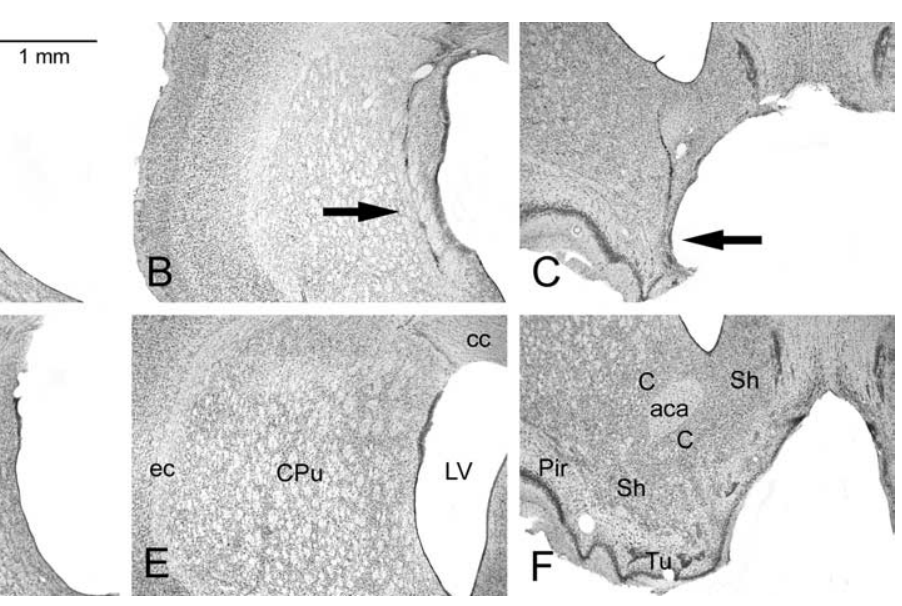
CPu lesion; $\boldsymbol{B}$, a medial mCPu lesion; $\boldsymbol{C}$, a ventral VSt lesion; $\boldsymbol{D}$, a lateral ICPu lesion; $\boldsymbol{E}$, control caudate-putamen; $\boldsymbol{F}$, control ventral striatum. Scale bar: (in $\boldsymbol{A}) \boldsymbol{A}-\boldsymbol{F}, 1 \mathrm{~mm}$. LV, Lateral ventricle; ec, external capsule; cc, corpus callosum; aca, anterior commissure, anterior part; Pir, piriform cortex; Tu, olfactory tubercle; $C$, core area of nucleus accumbens; Sh, shell area of nucleus accumbens. scriptions of the lesions.

Significant interaction effects were followed up with analyses to determine the source of the interaction.

Histology. After completion of behavioral testing, all animals were killed under deep anesthesia (100 mg/kg, i.m. ketamine and $10 \mathrm{mg} / \mathrm{kg}$, i.m. xylazine) by transcardiac perfusion of physiological saline immediately followed by $5 \%(\mathrm{v} / \mathrm{v})$ neutral buffered formalin. The brain was removed and submerged in a $10 \%$ glycerin/4\% neutral buffered formalin solution followed by $72 \mathrm{~h}$ in $20 \%$ glycerin/4\% neutral buffered formalin. Tissue was blocked in the plane by Paxinos and Watson (1998) using an RBM 4000C mold (ASI Instruments, Warren, MI) and sectioned frozen in the coronal plane at $30 \mu \mathrm{m}$. Every fifth slice was mounted and stained with thionin.

After chronic recovery, excitotoxic lesions produced by NMDA are associated with substantial tissue loss surrounding areas of dense gliosis (Fig. 2). To determine the extent of tissue damage, we performed quantitative analyses to measure the anteroposterior (AP) extent of lesions and the amount of striatal tissue remaining in coronal sections 1.6 and $0.5 \mathrm{~mm}$ anterior to bregma. To do this, we defined the most anterior section in which the corpus callosum crossed the midline as AP $1.6 \mathrm{~mm}$ and the most anterior in which the anterior commissure crossed midline as AP $0.0 \mathrm{~mm}$, relative to bregma. The anterior and posterior extents of lesions were determined by counting sections from these landmarks to the most anterior and posterior sections in which lesions damaged their intended targets bilaterally. Digital images were captured for the sections closest to AP 1.6 and $0.5 \mathrm{~mm}$ in front of bregma using a Spot RT color imaging system with Spot Advanced software (version 4.5.7b7) (Diagnostic Instruments, Sterling Heights, MI). The overall area of dorsal striatum was measured from the lateral ventricle along the ventral and medial surfaces of the corpus callosum and external capsule and across the upper margin of nucleus accumbens. The overall area of ventral striatum was measured below this region to the dorsal surface of the endopiriform nucleus, ventral pallidum, and olfactory tubercle and along the medial border of nucleus accumbens to the lateral ventricle minus the area of the anterior commissure enclosed by these borders. For both dorsal and ventral measures, the area of tissue damaged (within the borders) was subtracted from the measure of overall area to define the area of striatum spared by lesions. Comparable measurements were made for control as well as lesioned animals and the extent of damage estimated by comparing results for individual lesions from the average values of the control group.

\section{Results \\ Histology}

Histological sections were examined for all 42 animals that recovered uneventfully from surgery. Quantitative analyses were re- 


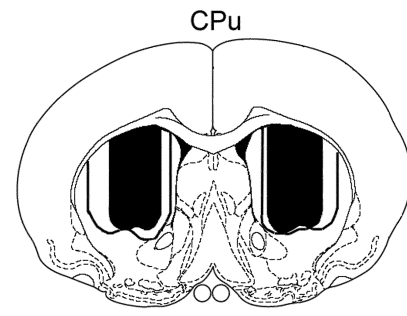

$\mathrm{ICPu}$

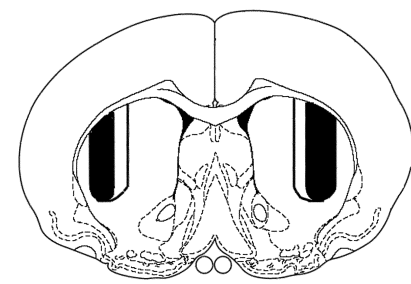

Figure 3. Drawings of the largest (unfilled) and smallest (filled) amounts of damage produced by each of the four lesions. The drawings are based on quantitative measurements at 0.5 $\mathrm{mm}$ from bregma (see Materials and Methods for details). Drawings are on templates derived from Paxinos and Watson (1998) with permission from the publisher.

stricted to the 38 that were included in the serial reaction time analyses. Lesions were marked by proliferation of microglia and loss of neurons, typically associated with enlarged ventricles, cavitation, and other signs of tissue loss (Fig. 2). The lCPu lesions spared tissue throughout the medial half and in more limited areas of ventrolateral caudate-putamen. The $\mathrm{mCPu}$ lesions spared tissue throughout the lateral half and in a thin medial band adjacent to the lateral ventricle. $\mathrm{CPu}$ lesions damaged the combination of areas affected by $\mathrm{lCPu}$ and $\mathrm{mCPu}$ lesions, typically sparing tissue in ventrolateral areas and in a medial band along the lateral ventricle of caudate-putamen. VSt lesions damaged extensive portions of the shell and core areas of nucleus accumbens and typically involved overlying areas of caudate-putamen and adjacent portions of the olfactory tubercle and ventral pallidum. Medial shell areas along the medial wall of the lateral ventricle were spared. Figure 3 shows areas damaged by the largest and smallest lesions (based on quantitative analyses below), as reconstructed from measures of the areas spared in tissue examined histologically.

Quantitative analyses confirmed that lesions affected the anteroposterior extent targeted by stereotaxic surgeries for all animals. The area of tissue spared in dorsal and ventral striatum was measured for all 38 animals studied at AP 1.6 and for 37 of 38 animals at $\mathrm{AP} 0.5$. Relative to controls, the $\mathrm{CPu}$ group lost $77.0 \%$ of tissue in dorsal striatum compared with $38.5 \%$ for the $\mathrm{mCPu}$, $28.9 \%$ for the $1 \mathrm{CPu}$, and $15.3 \%$ for the VSt groups. In contrast, the VSt group lost $67.9 \%$ of tissue in ventral striatum compared with $12.0 \%$ for the $\mathrm{CPu}, 2.5 \%$ for the $\mathrm{mCPu}$, and $2.0 \%$ for the $1 \mathrm{CPu}$ groups. ANOVAs revealed significant overall differences between groups in tissue spared within ventral striatum at both $\operatorname{AP} 1.6\left(F_{(4,33)}=36.650 ; p<0.0001\right)$ and AP $0.5\left(F_{(4,32)}=32.609\right.$; $p<0.0001$ ). Post hoc (Tukey-Kramer, $\alpha=0.05$ ) analyses showed significantly less tissue in ventral striatum for the VSt group than for all other groups. There were significant differences between groups for tissue spared in dorsal striatum at AP $1.6\left(F_{(4,33)}=\right.$ 82.134; $p<0.0001)$ and AP $0.5\left(F_{(4,32)}=82.221 ; p<0.0001\right)$. Post hoc (Tukey-Kramer, $\alpha=0.05$ ) analyses showed significantly less tissue in the $\mathrm{CPu}$ group compared with all other groups and in the $\mathrm{mCPu}$ and $\mathrm{lCPu}$ groups compared with the control and VSt groups. The differences between the $\mathrm{mCPu}$ and $\mathrm{lCPu}$ groups did not reach statistical significance.

\section{Single nose poke responses}

$\mathrm{CPu}$ and $\mathrm{mCPu}$ lesions had significant effects on speed and accuracy of responding to ports, indicated by brief luminance cues (Fig. 4). Four rats with complete $\mathrm{CPu}$ lesions did not respond consistently enough to produce usable results. The remaining four in this group had high response omission rates that precluded their inclusion in analyses of response accuracy. All other groups were more accurate at longer stimulus durations, performing above $85 \%$ correct for $3.0 \mathrm{~s}$ and below $30 \%$ correct for $0.05 \mathrm{~s}$ stimuli. The $\mathrm{mCPu}$ and (to a lesser extent) $\mathrm{lCPu}$ lesions tended to increase RT and decrease percentage correct, whereas VSt lesions had no apparent effect on choice responses. A twofactor (lesion group-by-stimulus duration) ANOVA showed that percentage correct was significantly affected by lesion group $\left(F_{(3,28)}=6.932 ; p=0.0012\right)$, stimulus duration $\left(F_{(5,140)}=\right.$ 643.739; $p<0.0001)$, and the interaction of these factors $\left(F_{(15,140)}=2.823 ; p=0.0007\right)$. Analyses of simple main effects revealed significant differences between groups at all but the shortest $(0.05 \mathrm{~s})$ stimulus duration $(p<0.02)$. Post hoc analyses (Tukey-Kramer, $\alpha=0.05$ ) showed significant differences between the $\mathrm{mCPu}$ and VSt groups for the $0.11,0.26,0.58,1.33$, and $3.0 \mathrm{~s}$ durations and between the $\mathrm{mCPu}$ and control groups at the $0.26,0.58,1.33$, and $3.0 \mathrm{~s}$ durations.

RT was divided into two components. Runway RT, the time taken to move down the alley and break the photo beam after pressing the lever, measures a response executed without modification on all trials. Choice RT, the time taken to execute a choice response after breaking the runway photo beam, measures a response that must by guided by luminance cues. Choice RTs (mean, $1.64 \mathrm{~s}$ ) tended to be longer than runway RTs (mean, $0.91 \mathrm{~s}$ ), although travel distances for each of these responses were comparable (35 cm for choice and $40 \mathrm{~cm}$ for runway responses). On average, $\mathrm{CPu}, \mathrm{mCPu}$, and $\mathrm{lCPu}$ lesions increased both $\mathrm{RT}$ measures, although effects on choice RT were substantially larger (Fig. 4). A two-factor (lesion group-by-RT measure) ANOVA showed a significant effect of lesion group $\left(F_{(4,31)}=16.526 ; p<\right.$ $0.0001)$, RT measure $\left(F_{(1,31)}=210.338 ; p<0.0001\right)$, and for the interaction of these factors $\left(F_{(4,31)}=5.244 ; p<0.0001\right)$. This interaction is consistent with a previous report that $\mathrm{mCPu}$ and $\mathrm{lCPu}$ lesions have greater effects on choice than runway RT for a similar task (Mair et al., 2002). We explored the interaction effect by analyzing simple main effects for runway and choice RT. These analyses showed significant differences between groups for both runway $\left(F_{(4,31)}=8.853 ; p<0.0001\right)$ and choice $\left(F_{(4,31)}=15.935\right.$; $p<0.0001$ ) RT. Post hoc analyses (Tukey-Kramer, $\alpha=0.05$ ) showed significantly higher RTs for the CPu group than all other groups for both measures. The $\mathrm{mCPu}$ group had higher RTs than the control and VSt groups for choice, but not for runway, responses. The $\mathrm{CPu}$ group also made substantially more errors of omission than the other groups (Fig. 4). A one-factor ANOVA showed a significant difference between groups for the percentage of trials on which errors of omission were committed $\left(F_{(4,31)}=25.096 ; p<0.0001\right)$. Post hoc (Tukey-Kramer, $\alpha=$ $0.05)$ analyses confirmed that the $\mathrm{CPu}$ group made more frequent omissions than any other group.

\section{Effects of repetition: single nose poke responses}

Short-term effects

When the location of the $S+$ was held constant for blocks of seven trials, percentage correct for brief $(0.05 \mathrm{~s})$ stimuli improved comparably for the $\mathrm{mCPu}, \mathrm{CPu}, \mathrm{VSt}$, and control groups. Rats with complete $\mathrm{CPu}$ lesions did not respond consistently to these stimuli and were thus excluded from the task. One rat in the $\mathrm{mCPu}$ 
group was excluded from analyses because of failure to complete a sufficient number of trials. All groups were highly accurate responding to the $3.0 \mathrm{~s}$ stimuli $(98.3 \%$ correct on average) and showed little change between trials 2, 4, and 6 in each block (Fig. 5). Responses to 0.05 s stimuli improved across trials 1, 3, 5, and 7 from an average of $37.4-63.5 \%$ correct, providing a clear indication of short-term learning. The mCPu group was less accurate overall responding to the $0.05 \mathrm{~s}$ stimuli but showed comparable improvement with repetition. Thus, there was no indication that any of the lesions affected short-term learning. For the $0.05 \mathrm{~s}$ stimuli, a two-factor (group-by-trial) ANOVA of percentage correct showed significant effects of lesion group $\left(F_{(3,27)}=3.020 ; p=0.0470\right)$ and trial number $\left(F_{(3,81)}=\right.$ 49.562; $p<0.0001)$, which did not interact $(F<1)$. Post hoc (Tukey-Kramer, $\alpha=0.05$ ) analyses revealed significant impairment of the $\mathrm{mCPu}$ group compared with all other groups. There was little change in RT across trials. On average, responses to $3.0 \mathrm{~s}$ stimuli decreased from 1.28 to $1.25 \mathrm{~s}$ from trial 2 to trial 6 , and responses to $0.05 \mathrm{~s}$ stimuli increased from 1.59 to $1.61 \mathrm{~s}$ from trial 1 to trial 7.

\section{Long-term effects}

Presenting a $3.0 \mathrm{~s}$ stimulus repeatedly in the same location across five sessions had little effect on RT (Fig. 6). There were substantial differences in overall RT between lesion groups. An ANOVA showed a significant effect of lesion group $\left(F_{(4,35)}=15.105 ; p<\right.$ 0.0001 ) but not of session type (random vs repeated location; $\left.F_{(1,35)}=1.281 ; p=0.2654\right)$. Analyses of the five sessions in which the $\mathrm{S}+$ port was held constant again revealed a significant effect of lesion group $\left(F_{(4,35)}=17.888 ; p<0.0001\right)$ but not of session or for the interaction of these factors $(F<1)$. Post hoc analyses (Tukey-Kramer, $\alpha=0.05$ ) showed that the CPu group was slower than all other groups and that the $\mathrm{mCPu}$ group was slower than the VSt and control groups for both random and repeat and slower than the $\mathrm{lCPu}$ group for the repeat trials.

\section{Effects of repetition on serial reaction time responding}

\section{Response initiation}

Analyses of serial reaction time results revealed increased RT to initiate repeated sequences that were apparent for all groups and exacerbated by $\mathrm{CPu}$ and $\mathrm{mCPu}$ lesions. The initial nose pokes in serial reaction time trials were identical to the long-term single nose poke learning task. Thus results for these tasks can be compared directly to determine the effects of repetition learning on RT to initiate single versus multiple nose poke responses (Fig. 6). On average, rats took more time to initiate sequential than single nose poke responses ( 3.47 vs $1.40 \mathrm{~s}$ ). When the location of S+ stimuli was held constant, RT increased more substantially for the first nose poke in sequential ( $4.08 \mathrm{vs} 2.87 \mathrm{~s})$ than single $(1.42$ vs $1.38 \mathrm{~s}$ ) nose poke responses. The effects of sequence length and repetition were substantially greater for the $\mathrm{mCPu}$ and $\mathrm{CPu}$ lesion groups. These trends were confirmed by a three-way ANOVA showing significant effects on initial nose poke RT of sequence length (one vs five nose pokes; $F_{(1,33)}=48.246 ; p<$ 0.0001 ), sequence type (repeat vs random; $F_{(1,33)}=25.891 ; p<$ $0.0001)$, and treatment group $\left(F_{(4,33)}=12.168 ; p<0.0001\right)$. There were significant interactions between sequence type and length $\left(F_{(1,33)}=21.853 ; p<0.0001\right)$, consistent with the greater

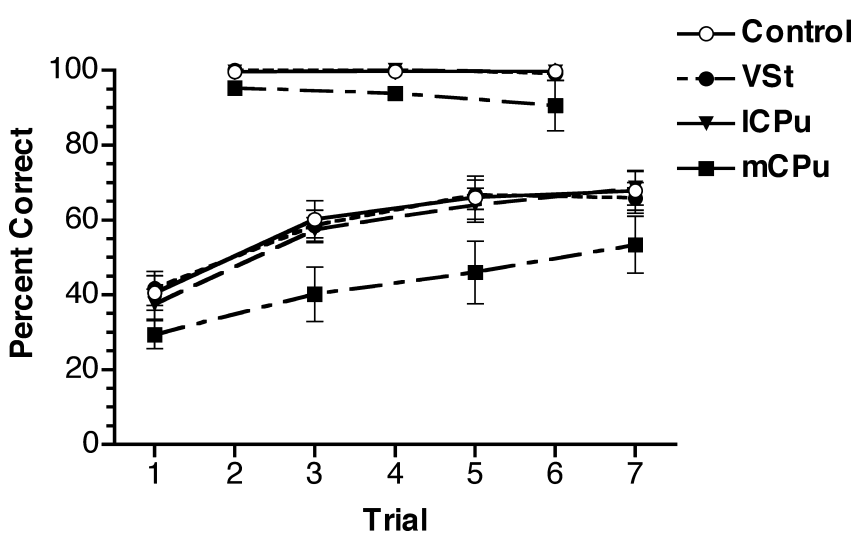

Figure 5. Short-term learning plotted as percentage correct for blocks of seven trials in which the location of the $S+$ port was held constant. Stimulus duration was $0.05 \mathrm{~s}$ for trials 1 , 3,5 , and 7 and 3.0 s for trials 2, 4, and 6 of each block. Rats with CPu lesions did not complete a sufficient number of trials for inclusion in analyses. There were few errors for $3.0 \mathrm{~s}$ stimuli. Percentage correct for the $0.05 \mathrm{~s}$ stimuli increased incrementally as they were repeated. Rats in the $\mathrm{mCPu}$ group were less accurate on average but exhibited increased accuracy with repetition comparable with other groups. The performances of the control, VSt, and ICPu groups were highly similar and thus overlap extensively in this figure. Error bars represent SEM.

effect of repetition on the initiation of sequences, as well as between sequence length and group $\left(F_{(4,33)}=5.428 ; p=0.0018\right)$ and sequence type and group $\left(F_{(4,33)}=4.246 ; p=0.0070\right)$, consistent with the greater effect of sequence length and repetition on the $\mathrm{mCPu}$ and $\mathrm{CPu}$ groups. The critical trends of responding slower initiating random sequence than single nose poke responses and repeated than random sequences were confirmed by separate ANOVAs for each of the groups. These analyses showed significant differences $(\alpha=0.05)$ for both trends for the control, $\mathrm{mCPu}, \mathrm{CPu}$, and VSt groups. The $\mathrm{lCPu}$ group showed similar trends, but these did not reach statistical significance.

\section{Incremental changes in $R T$}

The temporal course of serial reaction time learning was analyzed over the 10 sessions in which sequence A was repeated. On average, RT to complete sequence A increased over the first three sessions (from 9.78 to $11.73 \mathrm{~s}$ ), stabilized over several sessions, and then decreased to an average of $9.54 \mathrm{~s}$ by session 10. Analyses of individual nose pokes averaged across the 10 sessions revealed increases in RT for the first two nose pokes and decreases in RT for the last three nose pokes in sequence A compared with random sequences (Fig. 7E). Analyses of short-term (Fig. 7A,B) and long-term (Fig. 7C,D) effects of repetition showed that these differences developed gradually across sessions as sequence A was repeated. 


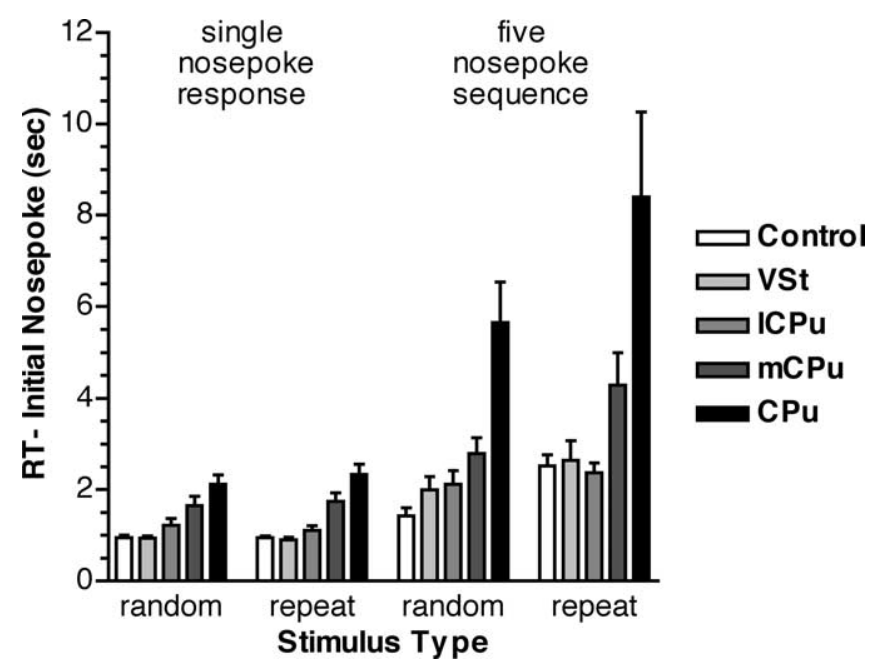

Figure 6. RT to make initial nose pokes in single nose poke and five nose poke serial reaction time responses. Results are presented for sessions in which discriminative stimuli changed randomly on each trial (random) and in which they were repeated unchanged on every trial (repeat). All groups were faster initiating single nose pokes than five nose poke sequences and sequences that were unpracticed (random) than those that were well practiced (repeat). These effects were exacerbated for rats with $\mathrm{mCPu}$ and CPu lesions. Error bars represent SEM.

To examine short-term effects of repetition, we compared responding during the first session in which sequence A was repeated (A1) with the preceding session (R1) in which sequences changed randomly on each trial. Individual performances were divided into five blocks of 12 for each session of 60 trials. The $\mathrm{CPu}$ group failed to complete a sufficient number of trials to do this and was thus excluded from the analysis. For each block, median $\mathrm{RT}$ was determined for each nose poke response for individual animals and results for session R1 subtracted from session A1. Positive values indicate increased RT during the repeated sequence session. During the first block of 12 trials, there were no overall differences between sessions $\mathrm{R} 1$ and A1. The effects of repetition emerged during subsequent blocks of A1, with RT increasing for the first two nose poke responses and decreasing marginally for the last three nose pokes in the repeated sequence. A three-factor ANOVA showed significant main effects for training block $\left(1-5 ; F_{(4,104)}=6.477 ; p=0.0001\right)$ and response number (first two vs last three nose pokes; $F_{(1,26)}=18.244 ; p=$ $0.0002)$ but not for treatment group $(F<1)$. There was a significant interaction between training block and response number, indicative of the different effects of repetition on the first two versus the last three responses in sequence A (compare Fig. $7 A, B$ ) $\left(F_{(4,104)}=11.472 ; p<0.0001\right)$. Analyses of simple main effects revealed significant increases in RT for the first two nose pokes $\left(F_{(4,104)}=10.375 ; p<0.0001\right)$, which interacted with the effects of treatment group $\left(F_{(12,104)}=2.433 ; p=0.0079\right)$. The decrease in RT for the last three responses was not significant and did not interact with the effects of group $(F<1)$.

To examine long-term effects of sequence learning, we compared responding across the 10 sessions in which sequence $A$ was repeated to responding during the random sequence sessions that occurred immediately before (R1), in the middle (R2), and immediately after (R3) these sessions. For each rat, median RTs were determined for each of the five nose pokes constituting sequences for a given session. RTs for random sequence sessions were averaged and subtracted from RTs for each of the 10 sessions in which sequence $A$ was repeated. Positive values for this measure indicate increased RT for repeated sequence sessions. This analysis showed continuation of trends apparent in session A1, with RTs for the first two responses increasing and remaining elevated compared with random sequence sessions and RTs for the last three responses decreasing incrementally across the 10 sessions. Rats with $\mathrm{mCPu}$ and $\mathrm{CPu}$ lesions showed larger increases in $\mathrm{RT}$ for the first two responses beginning with the third session (Fig. $7 C, D)$. A three-factor ANOVA revealed significant effects of treatment group $\left(F_{(4,33)}=7.284 ; p=0.0003\right)$, session (A1 to A10; $F_{(9,297)}=2.458 ; p=0.0103$ ), and response number (first two vs last three nose pokes; $\left.F_{(1,33)}=47.116 ; p<0.0001\right)$. There were significant interactions between: response number and group $\left(F_{(4,33)}=5.455 ; p=0.0017\right)$, indicative of differential increase in initial $\mathrm{RT}$ for the $\mathrm{CPu}$ and $\mathrm{mCPu}$ groups; session and group $\left(F_{(36,296)}=2.607 ; p<0.0001\right)$, indicative of the overall increase in $\mathrm{RT}$ for the $\mathrm{mCPu}$ and $\mathrm{CPu}$ groups; response number and session $\left(F_{(9,297)}=3.981 ; p<0.0001\right)$, indicative of the increase in RT for the first two responses compared with the decrease in RT for the last three responses; and the three-way interaction between response number, group, and session $\left(F_{(36,297)}=2.534 ; p<\right.$ $0.0001)$. Analyses of simple main effects revealed a significant increase in RT across sessions for the first two responses $\left(F_{(9,36)}=\right.$ 3.141; $p=0.0012)$, which interacted with treatment group $\left(F_{(36,297)}=2.783 ; p<0.0001\right)$, and a significant decrease in RT for the last three responses $\left(F_{(9,36)}=3.235 ; p=0.0009\right)$, which did not interact with group $(F<1)$. There was a significant difference between groups for the first two responses $\left(F_{(4,33)}=\right.$ $6.455 ; p=0.0006)$ but not for the last three $\left(F_{(4,33)}=1.032 ; p=\right.$ 0.4052 ). Post hoc analyses (Tukey-Kramer, $\alpha=0.05$ ) showed greater increases in $\mathrm{RT}$ for the first two responses for the $\mathrm{mCPu}$ and $\mathrm{CPu}$ groups compared with the lCPu, VSt, and control groups.

\section{Interference effects}

Analyses of interference effects confirmed the increase in RT for initial nose pokes and the decrease for later nose pokes in learned sequences. Interference effects are observed when a subject trained to respond to a constant repeating sequence is shifted abruptly to training with sequences that change randomly on every trial (Nissen and Bullemer, 1987; Nissen et al., 1989; Christie and Dalrymple-Alford, 2004). When RT decreases with sequence learning, it should increase when training is switched from repeated to random sequences (positive interference effect). The opposite effect should occur when sequence learning increases RT and RT decreases when switched to random sequences (negative interference effect). There were three transition points at which interference effects could be measured: between the fifth session of sequence $A$ and the second random session (A5/R2), the 10th session of sequence $A$ and the third random session (A10/R3), and the fifth session of sequence B and the fourth random session (B5/R4). We subtracted the RT for each response in the learned sequence from the corresponding response in the subsequent random sequence session (Fig. 8). Positive scores indicate that RTs increased at the transition from practiced to random sequences (i.e., that learning reduced RT).

The control group exhibited a consistent pattern of interference at each of the transitions: RTs decreasing significantly for the initial nose poke (negative interference) and increasing significantly for the last nose poke (positive interference). Each of the lesion groups showed similar results, although the absolute magnitude of interference effects differed between groups. For both the $\mathrm{mCPu}$ and VSt groups, there were significant decreases in RT for the first response and increases in RT for the last response. The $\mathrm{CPu}$ and $\mathrm{lCPu}$ groups showed similar trends, although only the increase in the last response for the $\mathrm{lCPu}$ group was statisti- 
cally significant. A three-factor (group-bytransition-by-response) ANOVA showed no difference between the three transitions scores or interaction between transition and group $(F<1)$; thus, data were combined for the three transitions for a two-factor (group-by-response) ANOVA. This analysis revealed significant effects of group $\left(F_{(4,33)}=3.056 ; p=0.0301\right)$, response $\left(F_{(4,132)}=12.660 ; p<0.0001\right)$, and the interaction between these factors $\left(F_{(16,132)}=2.370 ; p=0.0039\right)$.

\section{Behavioral-anatomical correlations}

Correlational analyses were performed to compare behavioral performances to measures of tissue damage in dorsal and ventral striatum. Cross-sectional areas at 1.6 and $0.5 \mathrm{~mm}$ from bregma were averaged to produce an overall measure of tissue remaining in dorsal and ventral striatum. These were then correlated with measures of behavioral performance, including: percentage omissions, percentage correct, runway RT, and choice RT for single nose poke responses; the difference in initial RT for single versus sequential nose poke responses when stimuli varied randomly on every trial; the difference in initial RT for sessions when sequences were varied randomly versus repeated on every trial; the difference in percentage correct for response 1 versus 7 when $S+$ was held constant (short-term habit learning); and interference effects averaged for initial (1 and 2$)$ versus final $(3,4,5)$ nose pokes in repeated sequences.

When analyses were performed within treatment groups (with limited variability in anatomical measures), there were no significant behavioral-anatomical correlations. When analyses were performed across groups (Table 2), there were significant correlations consistent with analyses of differences between treatment groups (described above). Rats with less tissue (more damage) in dorsal striatum had significantly more omissions, lower percent-

age correct, and longer runway and choice RTs. Dorsal striatal volume also correlated significantly with the differences between RTs for initiating sequential versus single nose poke responses and repeated versus random sequences and with the extent of (negative) interference for initial nose pokes. Dorsal striatal volume did not correlate significantly with measures of short-term habit learning or positive interference for later responses in repeated sequences. There were no significant correlations between measures of ventral striatal volume and any of these behavioral measures.

\section{Discussion}

\section{Effects of repetition on serial reaction time performance}

We sought to differentiate between the effects of repetition on the initiation and execution of learned sequences by analyzing individual nose pokes in serial reaction time sequences with defined
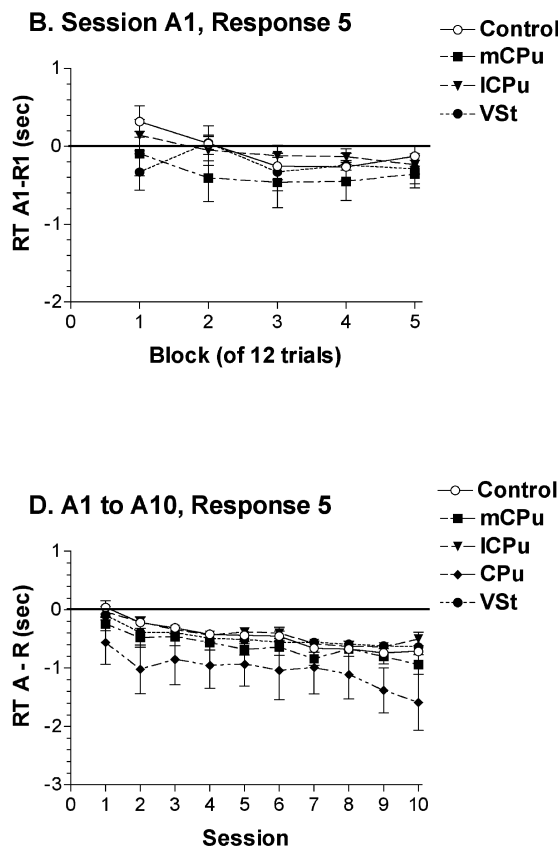

Figure 7. Incremental changes in RT for repeated serial reaction time sequences. $A, B$, The effects of repetition during the initial session in which sequence $A$ was repeated. This was measured for individual animals by dividing sessions R 1 and $A 1$ into five blocks of 12 responses and subtracting median RTs for R1 from A1. Positive values indicate increased RT for the repeated sequence decrease in RT to complete repeated sequences. $\boldsymbol{C}, \boldsymbol{D}$, The effects of repetition across the 10 sessions in which sequence $A$ was

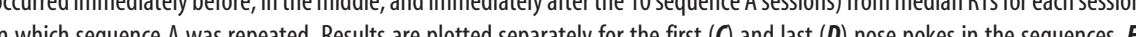
Median RTs for each response in serial reaction time sequences averaged across sessions in which sequence $A$ was repeated compared with random sessions R1, R2, and R3. Error bars represent SEM.

start and end points that were limited to five elements to avoid the effects of chunking (Kennerley et al., 2004). All groups showed predicted increases in RT for initial responses coupled with decreases in RT for later responses in sequences that emerged across sessions as sequences were repeated. These gradual changes were confirmed by interference effects observed when random sequences replaced repeated ones.

Two factors appeared to contribute to the long initial RT in repeated sequences (Fig. 6). First, RT was shorter for single nose poke responses $(0.95 \mathrm{~s})$ than for otherwise identical nose pokes that began random sequences $(1.43 \mathrm{~s})$. This suggests that RT is increased when rats anticipate a sequential rather than a single nose poke response, even when the specific locations of nose pokes are unpredictable. Second, RT was increased more for initial nose pokes in repeated than random sequences $(2.52$ vs 


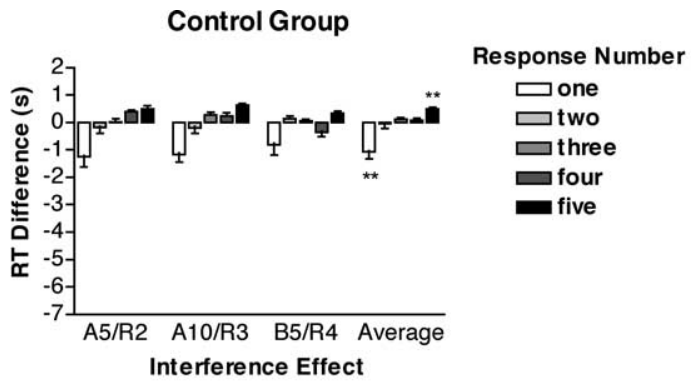

mCPu Lesion Group

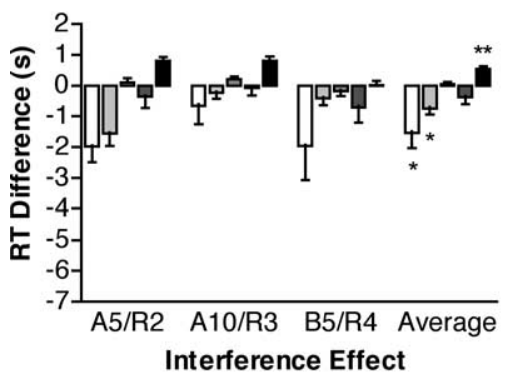

CPu Lesion Group

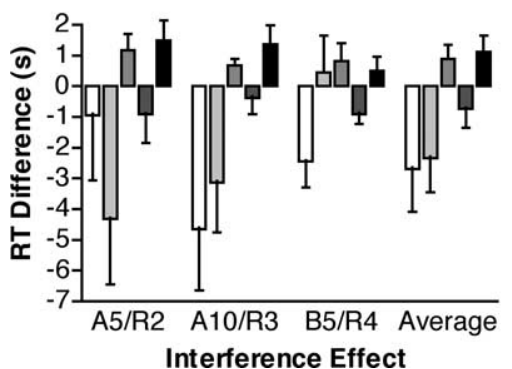

ICPu Lesion Group

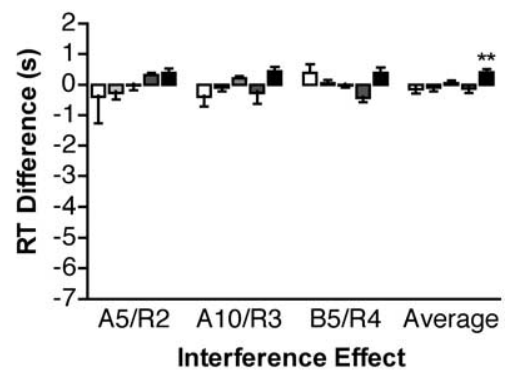

VSt Lesion Group

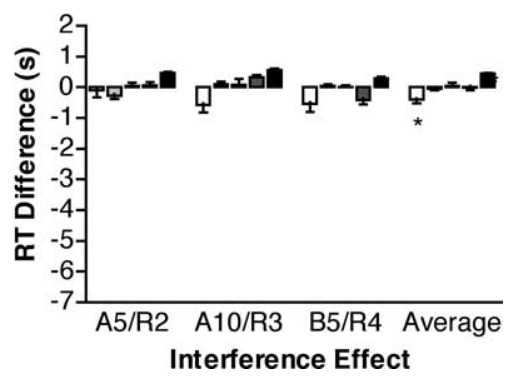

Figure 8. Interference effects measured as differences in RT for individual responses in repeated and random serial reaction time sequences. Positive scores indicate longer RTs for random sequences (beneficial effects of repetition). Results are reported for the transition from the fifth session with sequence $A$ to the second random session (A5/R2), the 10th session with sequence $A$ to the third random session (A10/R3), the fifth session with sequence $B$ to the fourth random session (B5/R4), and the average of these three transitions. Error bars represent SEM. For the average scores, significant interference effects (absolute differences $>0$, two-tailed $t$ test) are indicated by ${ }^{*} p<0.05$ or ${ }^{* *} p<0.01$.

Table 2. Summary of behavioral-anatomical correlations

\begin{tabular}{|c|c|c|c|c|}
\hline \multirow[b]{2}{*}{ Behavioral measure } & \multicolumn{2}{|c|}{ Dorsal striatum } & \multicolumn{2}{|c|}{ Ventral striatum } \\
\hline & $r$ value & $p$ value & $r$ value & $p$ value \\
\hline Single nose poke, omissions & -0.756 & $<0.0001$ & +0.166 & 0.360 \\
\hline Single nose poke, percentage correct & +0.719 & $<0.0001$ & -0.266 & 0.135 \\
\hline Single nose poke, runway RT & -0.765 & $<0.0001$ & +0.321 & 0.068 \\
\hline Single nose poke, choice RT & -0.703 & $<0.0001$ & +0.114 & 0.531 \\
\hline Initial RT, single versus sequential response & -0.605 & $<0.0001$ & +0.060 & 0.722 \\
\hline Initial RT, random versus repeated sequence & -0.457 & 0.0035 & +0.082 & 0.625 \\
\hline Short-term habit learning & -0.046 & 0.813 & +0.047 & 0.807 \\
\hline Interference, responses 1 and 2 & -0.562 & 0.0002 & +0.115 & 0.496 \\
\hline Interference, responses 3,4 , and 5 & +0.166 & 0.323 & -0.041 & 0.808 \\
\hline
\end{tabular}

$1.43 \mathrm{~s})$. This indicates, perhaps counterintuitively, that rats take longer to initiate a practiced sequence of nose pokes made in specific, repeated locations. This result is consistent with evidence that organizational demands affect RT to initiate an action, in this case increasing $\mathrm{RT}$ when rats prepare to execute a sequence versus a single nose poke directed at specific versus nonspecified locations (Sternberg et al., 1978; Inhoff et al., 1989; Kennerley et al., 2004). Analyses of sequence A indicate that initial RT increases gradually during the first few sessions in which sequences repeat (Fig. 7) and remain elevated (compared with random sequence sessions) through at least 10 sessions. These effects of repetition were confirmed by decreases in RT (negative interference) observed when repeating sequences were replaced with randomly changing ones (Fig. 8).

There appear to be two distinct processes that take place during serial reaction time learning. First, initial RT increases as individual actions are learned as a coherent sequence. Our results suggest that this effect emerges during the early stages of sequence learning. Second, RT to execute a sequence (once initiated) decreases gradually throughout training with a time course consistent with habit learning. Our results suggest that this effect is most apparent for later elements in sequences. It seems likely that both these effects would be more complex in longer sequences in which chunking is more of a factor. There are two confounding factors that may have affected these findings. First, reinforcement occurred after sequences ended and thus delay-to-reinforcement was longer for initial nose pokes in sequential than single nose poke responses. To the extent that this slowed responding, RT should decrease for responses 2-5 in random sequences. Contrary to this prediction, RTs increased across these responses (Fig. 7E). Second, differences in RT could reflect inherent differences in the particular sequences that were repeated. If this were a critical factor, there should have been stable differences throughout repeated sequence sessions and these should have shifted with the change from sequence A to B. Neither of these predictions was born out by the results.

\section{Effects of striatal lesions on serial reaction time learning}

VSt lesions had no significant effects and measures of ventral striatal volume did not correlate with any behavioral measures. We observed significant effects of $\mathrm{CPu}, \mathrm{mCPu}$, and $\mathrm{lCPu}$ lesions on single nose poke responses (Fig. 4), consistent with reports that dorsal striatum plays a critical role selecting or guiding routine motor responses based on external sensory stimuli (Brown and Robbins, 1989; Rogers et al., 2001; Mair et al., 2002). These group differences were confirmed by behavioral-anatomical correlations (Table 2). Rats with $\mathrm{mCPu}$ lesions were impaired for measures of response speed and accuracy. Although $\mathrm{lCPu}$ lesions alone did not produce significant deficits, their effects were in the 
same direction and significantly exacerbated impairments when combined with $\mathrm{mCPu}$ lesions in the $\mathrm{CPu}$ group. Rats with $\mathrm{CPu}$ and $\mathrm{mCPu}$ lesions continued to exhibit deficits in baseline performance throughout subsequent repetition learning tasks, consistent with a persistent underlying impairment in visually guided responding.

$\mathrm{RT}$ analyses suggest that $\mathrm{CPu}$ and $\mathrm{mCPu}$ lesions interfered with the initiation of learned sequences. All groups took longer to make initial nose pokes in repeating sequences. The $\mathrm{CPu}$ and $\mathrm{mCPu}$ groups exhibited larger increases in initial $\mathrm{RT}$ that built up across sessions in which sequences were repeated (Fig. 7). These increases translated into larger negative interference effects for the first two responses in learned sequences (Fig. 8). These results seem consistent with evidence that medial striatum plays a critical role in organizational processes that occur before the onset of learned action sequences (Sternberg et al., 1978; Kennerley et al., 2004). Medial striatum receives prominent projections from dorsal prefrontal cortical areas implicated in motor planning and response initiation (McGeorge and Faull, 1989; Sesack et al., 1989). Indeed, we found significant increases in initial RT for the present serial reaction time task for rats with lesions in these cortical areas (Bailey et al., 2004). Striatal neurons have been shown to respond before the onset of learned action sequences, consistent with a role in response initiation (Kermadi and Joseph, 1995; Lebedev and Nelson, 1999; Lee and Assad, 2003). Medial striatal lesions in rats have been shown to increase RT to initiate learned lateralized movements similar to the present task (Brown and Robbins,1989).

Although dorsal striatal lesions affected baseline levels of functioning, they did not interfere with incremental improvements in performance associated with repetition of discriminative stimuli. The mCPu group was impaired for percentage correct and RT responding to ports indicated by luminance cues. Nevertheless, they improved comparably to control, $1 \mathrm{CPu}$, and VSt groups when the location of the S+ port was held constant for seven consecutive trials (Fig. 5). Although $\mathrm{CPu}$ and $\mathrm{mCPu}$ groups were slower than controls (and other lesion groups) completing serial reaction time sequences, they showed incremental improvements in RT for responses 3, 4, and 5 that were comparable with controls (and other lesion groups) (Fig. 7). The benefits of habit learning, reflected in incremental decreases in RT and positive interference effects, were seen most reliably for the last response in repeated sequences, and these were spared by dorsal striatal lesions. The incremental improvements observed with $\mathrm{lCPu}, \mathrm{mCPu}$, and $\mathrm{CPu}$ lesions are surprising given the widely held view that dorsal striatum is a critical component of circuits that underlie habit learning (Graybiel, 1995, 1998; White, 1997; Packard and Knowlton, 2002). Serial reaction time tasks have been used widely with human subjects to demonstrate the effects of basal ganglia pathology on habit learning and to measure related neural activity in functional imaging studies.

Habit learning is typically measured by improvements in tasks that are performed repeatedly: an approach that confounds the ability to acquire new S-R associations with the ability to express them behaviorally. The effects of striatal lesions in the present study are consistent with the role the basal ganglia play in controlling movement. The impairment in visually guided responding, apparent for single nose poke responses, undoubtedly contributed to deficits observed in baseline performance throughout habit learning tasks. The serial reaction time task used here was intended to dissociate the effects of striatal lesions on the initiation and execution of a learned sequential habit. The effects of dorsal striatal lesions on RT for initial nose pokes are consistent with the role these areas are thought to play in programming behavioral actions before their execution. The consistent improvement for later elements across sessions indicates that these habits are either acquired and stored in some other part of the brain or that the limited portions of dorsal striatum surviving $\mathrm{CPu}$ lesions are sufficient to mediate this learning. Visual information reaches motor cortex through two main routes: a corticocortical route involving dorsal stream visual areas in the parietal lobe or a subcortical route involving pontine-cerebellar projections (Glickstein, 2000). Evidence has been presented of plastic changes in both these pathways during visuomotor learning that might account for the improvement of $\mathrm{CPu}$-lesioned rats in the present study (Hikosaka et al., 1998; Doyon et al. 2003; Parsons et al., 2005).

Graybiel (1998) proposed that the basal ganglia contribute to S-R learning by chunking representations of action sequences. Consistent with this, Christie and Dalrymple-Alford (2004) report that dorsal striatal lesions spare serial reaction time learning for sequences of four nose pokes but not for longer sequences of 8 or 12 nose pokes. The ability to learn the shorter sequence is in agreement with evidence in the present study that $\mathrm{CPu}$ and $\mathrm{mCPu}$ lesions spare basic aspects of habit learning. Results from both studies suggest that dorsal striatal lesions affect higher-level organization reflected in planning that precedes the execution of learned sequences or in sequence-specific learning (chunking) of longer action sequences.

\section{References}

Bailey KR, Mair RG (2004) Dissociable effects of frontal cortical lesions on measures of visuospatial attention and spatial working memory in the rat. Cereb Cortex 14:974-985.

Bailey KR, Zhang YP, Toupin MM, Mair RG (2004) Premotor and prefrontal cortical lesions affect time to initiate, but not learning-related changes in motor sequence responding. Soc Neurosci Abstr 30:771.8.

Brown RG, Redondo-Verge L, Chacon JR, Lucas ML, Channon S (2001) Dissociation between intentional and incidental sequence learning in Huntington's disease. Brain 124:2188-2202.

Brown VJ, Robbins TW (1989) Elementary processes of response selection mediated by distinct regions of the striatum. J Neurosci 9:3760-3765.

Burk JA, Mair RG (2001) Effects of dorsal and ventral striatal lesions on delayed matching trained with retractable levers. Behav Brain Res 122:67-78.

Christie MA, Dalrymple-Alford JC (2004) A new rat model of the human serial reaction time task: contrasting effects of caudate and hippocampal lesions. J Neurosci 24:1034-1039.

Daselaar SM, Rombouts SA, Veltman DJ, Raaijmakers JG, Jonker C (2003) Similar network activated by young and old adults during the acquisition of a motor sequence. Neurobiol Aging 24:1013-1019.

Dominey PF, Ventre-Dominey J, Broussolle E, Jennerod M (1997) Analogical transfer is effective in a serial reaction time task in Parkinson's disease: evidence for a dissociable form of sequence learning. Neuropsychologia 35:1-9.

Doyon J, Penhune V, Ungerleider LG (2003) Distinct contribution of the cortico-striatal and cortico-cerebellar systems to motor learning. Neuropsychologia 41:252-262.

Glickstein M (2000) How are visual areas of the brain connected to motor areas for the sensory guidance of movement? Trends Neurosci 23:613-617.

Graybiel AM (1995) Building action repertoires: memory and learning functions of the basal ganglia. Curr Opin Neurobiol 5:733-741.

Graybiel AM (1998) The basal ganglia and chunking of action repertoires. Neurobiol Learn Mem 70:119-136.

Hikosaka O, Miyashita K, Miyachi S, Sakai K, Lu X (1998) Differential roles of the frontal cortex, basal ganglia, and cerebellum in visuomotor sequence learning. Neurobiol Learn Mem 70:137-149.

Inhoff AW, Diener HC, Rafal RD, Ivry R (1989) The role of cerebellar structures in the execution of serial movements. Brain 112:565-581. 
Jackson GM, Jackson SR, Harrison J, Henderson L, Kennard C (1995) Serial reaction time learning and Parkinson's disease: evidence for a procedural learning deficit. Neuropsychologia 33:577-593.

Kennerley SW, Sakai K, Rushworth MFS (2004) Organization of action sequences and the role of the pre-SMA. J Neurophysiol 91:978-993.

Kermadi I, Joseph JP (1995) Activity in the caudate nucleus of monkey during spatial sequencing. J Neurophysiol 74:911-933.

Kim JS, Reading SA, Brashers-Krug T, Calhoun VD, Ross CA, Pearlson GD (2004) Functional MRI study of a serial reaction time task in Huntington's disease. Psychiatry Res 30:23-30.

Knopman D, Nissen MJ (1991) Procedural learning is impaired in Huntington's disease. Neuropsychologia 29:245-254.

Lebedev MA, Nelson RJ (1999) Rhythmically firing neostriatal neurons in monkey: activity patterns during reaction-time hand movements. J Neurophysiol 82:1832-1842.

Lee IH, Assad JA (2003) Putaminal activity for simple reactions or selftimed movements. J Neurophysiol 89:2528-2537.

Mair RG, Koch JK, Newman JB, Howard JR, Burk JA (2002) A double dissociation within striatum between serial reaction time and radial maze delayed nonmatching performance in rats. J Neurosci 22:6756-6765.

McGeorge AJ, Faull RLM (1989) The organization of the projection from the cerebral cortex to the striatum in the rat. Neuroscience 29:503-537.

Miyachi S, Hikosaka O, Miyashita K, Karadi, Rand MK (1997) Differential roles of monkey striatum in learning of sequential hand movement. Exp Brain Res 115:1-5.

Miyachi S, Hikosaka O, Lu X (2002) Differential activation of monkey striatal neurons in the early and late stages of procedural learning. Exp Brain Res 146:122-126.

Nissen MJ, Bullemer P (1987) Attentional requirements of learning: evidence from performance measures. Cognit Psychol 19:1-32.

Nissen MJ, Willingham D, Hartman M (1989) Explicit and implicit remembering: when is learning preserved in amnesia? Neuropsychologia 27:341-452.
Packard MG, Knowlton BJ (2002) Learning and memory functions of the basal ganglia. Annu Rev Neurosci 25:563-593.

Parsons MW, Harrington DL, Rao SM (2005) Distinct neural systems underlie learning visuomotor and spatial representations of motor skills. Hum Brain Mapp 24:229-247.

Paxinos G, Watson C (1998) The rat brain in stereotaxic coordinates, Ed 4 San Diego: Academic.

Peigneux P, Maquet P, Meulemans T, Destrebecqz A, Laureys S, Degueldre C, Delfiore G, Aerts J, Luxen A, Franck G, Van der Linden M, Cleeremans A (2000) Striatum forever, despite sequence learning variability: a random effect analysis of PET data. Hum Brain Mapp 10:179-194.

Rauch SL, Whalen PJ, Savage CR, Curran T, Kendrick A, Brown H, Bush G, Breiter HC, Rosen BR (1997) Striatal recruitment during an implicit sequence learning task as measured by functional magnetic resonance imaging. Hum Brain Mapp 5:124-132.

Rogers RD, Baunez C, Everitt BJ, Robbins TW (2001) Lesions in the medial and lateral striatum in the rat produce differential deficits in attentional performance. Behav Neurosci 115:799-811.

Sesack SR, Deutch AY, Roth RH, Bunney BS (1989) Topographical organization of the efferent projections of the medial prefrontal cortex in the rat: an anterograde tract-tracing study with Phaseolus vulgaris leucoagglutinin. J Comp Neurol 290:213-242.

Smith JG, McDowall J (2004) Impaired higher order implicit sequence learning on the verbal version of the serial reaction time task in patients with Parkinson's disease. Neuropsychology 18:679-691.

Sternberg S, Monsell S, Knoll RL, Wright CE (1978) The latency and duration of rapid movement sequences. In: Information processing in motor control and learning (Stelmach GE, ed), pp 117-152. New York: Academic.

White NM (1997) Mnemonic functions of the basal ganglia. Curr Opin Neurobiol 7:164-169.

Willingham D, Koroshetz W (1993) Evidence for dissociable motor skills in Huntington's disease patients. Psychobiology (Austin, Tex) 21:173-182. 